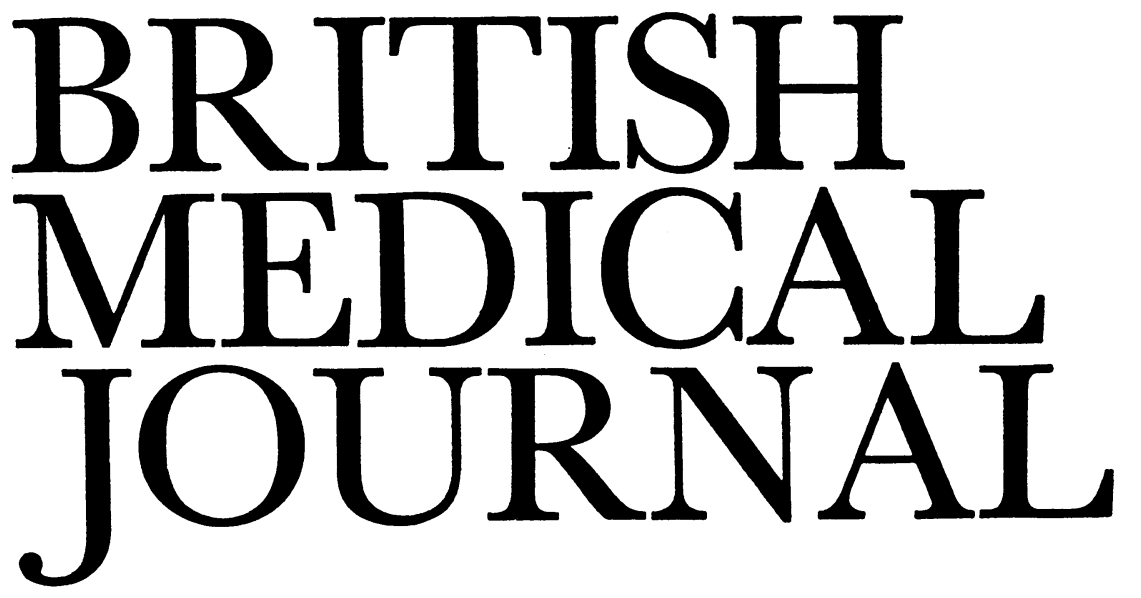

LONDON, SATURDAY 14 APRIL 1984

\title{
Benzodiazepines on trial
}

Anyone who believes that a drug treatment can combine sound efficacy with no adverse effects whatsoever must be due for a nasty fall. The benzodiazepines are excellent antianxiety drugs and hypnotics, ${ }^{12}$ superior in efficacy to other antianxiety drugs, including the barbiturates, ${ }^{34}$ and indubitably safer..$^{5}$ As soon as they became available prescriptions for benzodiazepines rose steadily, exceeding those for barbiturates in 1965, and they continued to climb dramatically during the 1970s. Their popularity provoked some concern, ${ }^{6}$ but careful investigations suggested that the drugs were being prescribed more or less responsibly, ${ }^{7}$ though patients tended to receive them for unduly long periods. ${ }^{8}$

With the discovery of specific binding sites for benzodiazepines in the central nervous system the reasons for their specificity in anxiety became clear. ${ }^{9}$ An endogenous substance similar in structure to the benzodiazepines must be concerned in the physiological control of anxiety: perhaps, their supporters claimed, exogenous benzodiazepines only mimicked a natural process.

In recent years, however, the pendulum of approval has swung dramatically against the benzodiazepines. Ashton's careful study ( $p$ 1135) is the latest of several investigations that have shown quite unequivocally that benzodiazepines may produce pharmacological dependence in therapeutic dosage. ${ }^{10-14}$ The typical pattern of a drug dependence syndrome, with drug seeking behaviour, rapid tolerance, and escalation of dosage, is rare (according to Marks's calculations, one in every 5 million patient months "at risk"15) but the occurrence of dependence after therapeutic dosage is more frequent and more alarming. This danger has been recognised for several years, ${ }^{16}$ but until recently clinicians have been reluctant to accept that the problems seen in patients taking benzodiazepines constitute true pharmacological dependence - partly because the dependence is manifested primarily by an abstinence syndrome occurring after the dose of the drug is reduced or treatment is stopped.

Much of the difficulty stems from the early symptoms of withdrawal being those of anxiety, so that when a patient becomes anxious after withdrawal of benzodiazepines this may be mistaken simply for a return of pre-existing anxiety. The full constellation of withdrawal features-including peculiar forms of perceptual disturbance (well exemplified by Ashton's cases), unusual somatic symptoms such as muscle stiffness, twitchings and paraesthesiae, dysphoria, psychotic disturbance, and epileptic fits-cannot be explained in this way. In its less florid form, however, the syndrome of dependence may develop insidiously and apparently unknown to the patient, so an increase of symptoms after reducing dosage of the drug may easily be interpreted as a return of anxiety, when treatment will be maintained rather than withdrawn.

Is the syndrome of benzodiazepine dependence qualitatively distinct from other drug dependence syndromes? The symptoms overlap considerably with other drug dependent states, but the perceptual disturbance seems to be a constant and unusual feature that may be specific. The more usual symptoms of withdrawal are greatly affected by expectation and may not always be reliable: for example, in one recent study $22 \%$ of patients experienced withdrawal symptoms at a time when they thought that their drugs were being withdrawn but the dosage had remained constant. ${ }^{14}$ In my clinical experience the diversity and severity of withdrawal symptoms have increased considerably in the past two years, but this may indicate only greater public awareness of the problemany strange symptom may now be labelled a withdrawal reaction. Personality seems important in the aetiology of the withdrawal syndrome: patients with passive and dependent personality characteristics are more liable to develop symptoms. ${ }^{14}$ By contrast, many patients can stop benzodiazepines after many years without any withdrawal symptoms. Though in Ashton's study (and that of Petursson and Lader ${ }^{13}$ ) all the patients studied had withdrawal symptoms, they had all tried previously to reduce or stop their benzodiazepines and only when they had failed were they referred for specialist treatment. In the more typical settings of general practice or psychiatric outpatient clinics many patients take benzodiazepines regularly and unnecessarily-and more than half can stop treatment without any important withdrawal symptoms..$^{1214}$

The best management for benzodiazepine dependence is far from clear. Treatment should not be stopped abruptly, for this is more likely to lead to serious withdrawal symptoms including epileptic seizures. Though gradual withdrawal may not prevent symptoms from developing, it may reduce their severity. If possible treatment with a short acting benzo- 
diazepine should be changed to a long acting preparation before withdrawal. A balance has to be struck between slow withdrawal, which prolongs the symptoms but tends to make them less severe, and fast withdrawal, which leads to more intense symptoms lasting for a shorter time. Though no pharmacological treatment will abort the withdrawal symptoms, propranolol will attenuate some features, ${ }^{12}$ and on the basis of experience with withdrawal of alcohol and opiates clonidine might be expected to have a place in treatment. In low dosage antipsychotic drugs are effective tranquillisers and have no risk of pharmacological dependence; but unfortunately they seem to have no value in treating the withdrawal syndrome. Indeed, one study with oxypertine suggested that such drugs might accentuate the withdrawal symptoms, possibly through their action in blocking dopamine receptors. ${ }^{17}$ On the other hand, simultaneous treatment with a sedative antidepressant such as trimipramine or amitriptyline seems to lessen many of the symptoms. The place of psychological treatment also needs investigating, but group therapy has little effect in helping patients to stop their benzodiazepines. ${ }^{18}$

In terms of public policy, now that benzodiazepines have been shown to cause drug dependence should their use be more closely controlled-or even banned? We need to remember that these drugs have an important place in the short term treatment of anxiety and insomnia and are often invaluable in anaesthesia and epilepsy. What is needed is for them to be prescribed more carefully and with better awareness of their dangers. A course of treatment lasting for only several weeks is not likely to lead to dependence-though the "safe" period of drug prescription before the risk of dependence is not yet known. Flexible dosage given up to an agreed maximum dose a day also helps to keep total drug dosage down. ${ }^{19}$ Although short term treatment is officially recommended, ${ }^{20}$ this advice is often ignored, and far too many repeat prescriptions are given without adequate assessment. Cross tolerance occurs among benzodiazepines, so that if dependence occurs with one it is likely to be transferred to another. Diazepam is the most commonly prescribed benzodiazepine and has attracted more adverse publicity than other compounds, but this opprobrium may be misplaced. Benzodiazepines with shorter duration of action, such as triazolam and lorazepam, may carry a greater risk of dependence than their longer acting relatives: certainly their withdrawal symptoms occur earlier and are more severe than those of long acting compounds. ${ }^{12} 2122$ The explanation may be that withdrawal symptoms are more likely when blood concentrations of benzodiazepines fall rapidly after stopping the drug. ${ }^{12}$ Indeed, the paradox may be that the attempt to make the prescription of benzodiazepines more acceptable by shortening their duration of action has led to a greater incidence of pharmacological dependence.

Finally, we should not assume that the long term prescription of benzodiazepines and the consequent high risk of dependence are evils to be avoided at all costs. No permanent consequences of dependence on benzodiazepines have been described, although Lader's findings of possible psychological impairment and neuroradiological changes after prolonged treatment need to be followed up. ${ }^{23}$ Cigarette smoking probably represents the closest pharmacological cousin of benzodiazepine dependence and is far more dangerous-as is the addiction to alcohol that the patient may take up as an alternative. Many patients can stop regular consumption of benzodiazepines but find it difficult to cope without the occasional tablet, and this practice may be condoned if not formally encouraged. ${ }^{24}$ Banning benzodiazepines is no answer to the problem of dependence. The response should be a period of probation and reassessment, not punishment.

P J TYRER

Consultant Psychiatrist,

Mapperley Hospital,

Nottingham NG3 6AA

${ }^{1}$ Randall LO, Schallek W, Heise GA, Keith EF, Bagdon RE. The psychosedative properties of methaminodiazepoxide. $\mathcal{F}$ Pharmacol Exp Ther 1960;120:163-71.

${ }^{2}$ Randall LO, Heise GA, Schallek W, et al. Pharmacological and clinical studies on Valium, a new psychotherapeutic agent of the benzodiazepine class. Current Therapeutic Research 1961 ; 3:405-25.

3 Jenner FA, Kerry RJ, Parkin D. A controlled comparison of methaminodiazepoxide and amylobarbitone in the treatment of anxiety in neurotic patients. Fournal of Mental Science 1961;107:583-9.

${ }^{4}$ McDowall A, Owen S, Robin AA. A controlled comparison of diazepam and amylobarbitone in anxiety states. Br $\mathcal{F}$ Psychiatry 1966;112:629-31.

${ }^{5}$ Matthew H, Proudfoot AT, Aitken RCB, Raeburn JA, Wright N. Nitrazepam-a safe hypnotic. Br Med f 1969 ;iii :23-5.

${ }^{6}$ Trethowan W. Pills for personal problems. Br Med f 1975;iii:749-51.

7 Mellinger GD, Balter MB, Manheimer DI, Cisin IH, Parry HJ. Psychic distress, life crisis, and use of psychotherapeutic medication. Arch Gen Psychiatry 1978;35:1045-52.

${ }^{8}$ Tyrer P. Drug treatment of psychiatric patients in general practice. Br Med f 1978; ii :1008-10.

${ }^{9}$ Möhler H, Okada T. Benzodiazepine receptor: demonstration in the central nervous system. Science $1977 ; 198: 849-51$.

${ }^{10}$ Pevnick JS, Jasinski DR, Haertzen CA. Abrupt withdrawal from therapeutically administered diazepam. Arch Gen Psychiatry 1978;35: 995-8.

11 Winokur A, Rickels K, Greenblatt DJ, Snyder PJ, Schatz NJ. Withdrawal reaction from long term, low dosage, administration of diazepam. Arch Gen Psychiatry 1980;37:101-5.

12 Tyrer $P$, Rutherford D, Huggett T. Benzodiazepine withdrawal symptoms and propranolol. Lancet $1981 ; \mathrm{i}: 520-2$.

${ }^{13}$ Petursson $\mathrm{H}$, Lader $\mathrm{MH}$. Withdrawal from long-term benzodiazepine treatment $\mathrm{Br}$ Med $\mathcal{F} 1981 ; 283: 643-5$.

${ }^{14}$ Tyrer P, Owen R, Dawling S. Gradual withdrawal of diazepam after chronic therapy. Lancet 1983;i:1402-6.

${ }^{15}$ Marks J. The benzodiazepines: use, overuse, misuse, abuse. Lancaster: MTP Press, 1978.

${ }^{16}$ Owen RT, Tyrer P. Benzodiazepine dependence: a review of the evidence. Drugs $1983 ; 25$ :385-98.

17 Petursson $\mathrm{H}$. Clinical and laboratory studies of withdrawal from longterm benzodiazepine treatment. London: University of London, 1983. $\mathrm{PhD}$ thesis.

18 Cormack MA, Sinnott A. Psychological alternatives to long-term benzodiazepine use. f $R$ Coll Gen Pract 1983;33:279-81.

19 Winstead DK, Anderson A, Eilers MK, Blackwell B, Zaremba AL. Diazepam on demand: drug seeking behavior in psychiatric in-patients. Arch Gen Psychiatry 1974;30:349-51.

${ }^{20}$ Committee on the Review of Medicines. Systematic review of the benzodiazepines. Br Med F 1980;280:910-2.

${ }^{21}$ Morgan K, Oswald I. Anxiety caused by a short-life hypnotic. $\mathrm{Br} \mathrm{Med} \mathcal{F}$ $1982 ; 284: 942$.

22 Tyrer $P$, Seivewright $N$. Identification and management of benzodiazepine dependence. Postgrad Med $\mathcal{f}$ (in press).

${ }^{23}$ Lader M. Benzodiazepines, psychological functioning and dementia. In: Trimble MR, ed. Benzodiazepines divided: a multidisciplinary review. Chichester: Wiley, 1983:309-22.

24 Tyrer P. Dependence on benzodiazepines. Br $\mathcal{F}$ Psychiatry 1980;137: 576-7.

\section{Protecting confidentiality}

Not very long ago a patient could feel absolutely confident that whatever personal details he or she gave to a doctor would remain confidential. That was at a time when no one else had any need to see whatever notes the doctor might have kept, since most treatment began and finished with the doctor himself. Patients were only rarely required to produce medical information for other purposes, and the chances of that information being divulged inadvertently to anyone not entitled to see it were very limited.

More recently, however, three developments have shaken 